\title{
Collecting Ego-centred Network Data via the Web
}

\author{
Katja Lozar Manfreda, Vasja Vehovar, and Valentina Hlebec ${ }^{1}$
}

\begin{abstract}
Owing to their complex data structure face-to-face surveys are a typical data collection method for ego-centred social networks. Usually the interviewer is required to handle the list of alters in order to reduce misunderstandings and typing errors and increase the respondents' motivation. When answering questions about each alter the respondent is given help. Compared to face-to-face or telephone interviews Web data collection can substantially reduce the costs, time, and fatigue in managing the complex questionnaire required for data collection of ego-centred data. Such data collection is especially suitable for special populations familiar with Internet tools. However, particular attention to questionnaire design has to be paid if a respondent is expected to complete a Web questionnaire by him or herself, compiling a list of alters and giving information about them.

One trial in the collection of ego-centred networks via the Web was performed during the annual RIS (Research on Internet in Slovenia) Web survey conducted by the Faculty of Social Sciences, University of Ljubljana. Respondents were randomly split into four groups. Each group received a name generator for one type of social support: material, informational, emotional support or social companionship. Each respondent also received a set of questions for each alter they named in the network generator. Data collection was carried out between June and October 2001. The quality of the data was studied with respect to the number of listed alters and by two question wording forms for name generators. The analysis shows that the Web can be used as a data collection method for ego-centred social networks. However, special attention is required when designing the graphic layout of name generators as well as with the wording of instructions. In particular, the number of alters should be limited in some way, since respondents who name many alters tend to quit the questionnaire before answering additional questions regarding these alters.
\end{abstract}

\footnotetext{
${ }^{1}$ University of Ljubljana, Faculty of Social Sciences; katja.lozar-manfreda@fdv.uni-lj.si
} 


\section{Introduction}

Several tasks have to be performed in measuring ego-centred social networks. First, the respondents (focal egos) list the names of existing ties (i.e. providers of one particular type of social support) via a so-called name generator ${ }^{2}$. When all ties (alters) have been identified, the characteristics of the listed alters and the characteristics of the ties linking egos to these alters (such as strength, reciprocity or multiplexity) have to be evaluated. The ego is the source that provides all this information. Owing to the complexity of the response tasks - compiling and editing the list of alters, recalling and writing facts about alters, recalling and evaluating characteristics of contacts with each of these alters, etc. - data about ego-centred networks is usually collected by face-to-face surveys.

A considerable number of authors have evaluated the methodological characteristics of various methods for collecting ego-centred network data. There are studies comparing the characteristics of the measured networks (e.g., Burt, 1984; Marsden, 1987; Wellman and Wortley, 1990), evaluating the measured networks using different network generators (e.g., Bernard et al., 1987; Milardo, 1989, Bernard et al., 1990; Campbell and Lee, 1991; Van der Poel, 1993) and evaluating the characteristics of the measured ties (e.g., Marsden and Campbell, 1984; Burt, 1986). There are also studies that have predominantly focused on the issue of network data quality (Hammer, 1984; Sudman, 1985, 1988; Hlebec, 1993, and Brewer and Webster, 1997), and on the reliability and validity of measured networks and data collection methods used (Van Groenou et al., 1990; HoffmeyerZlotnik, 1990; Tracy and Catalano, 1990; Bien et al., 1991; Neyer et al. 1991; Marsden, 1993; Ferligoj and Hlebec, 1999; Zemljič and Hlebec, 2001; Kogovšek et al., 2002; Hlebec and Ferligoj, 2002).

Most of these studies used only the face-to-face data collection mode. However, Kogovšek et al. (2002) compared face-to-face and telephone surveys and proved that ego-centred data can be collected in a reliable and valid way also by telephone. Nevertheless, there are significant variations in the network size and composition across data collection modes. Marsden (Marsden and Bailey, 1999; Marsden 2003) evaluated the GSS network generator (Burt, 1984), using cognitive methods to assess how the questionnaire position and the interviewer affect the network composition and size. Their analysis showed that network generators are less independent from the questionnaire context (placing a network generator in a certain position within a questionnaire - following various topics) than had been assumed, and that interviewers can influence the estimation of the network size. Straits (2000) compared two single name generators and a change of wording in a

\footnotetext{
2 A name generator is an open-ended survey question where the names (also nicknames, shortened names, etc.) of actual people providing social support to respondents are elicited.
} 
$2 \times 2$ factorial design. He used the GSS name generator ("discussing important matters" and "the most significant people in your life" name generators) and experimentally included a probe for negative interactions ("These may include people that sometimes make you angry or upset"). His analysis showed that two name generators produced similar networks; however the experimental probe for negative interactions produced statistically significant but substantively unimportant compositional differences. It seems that measurement quality should be studied more thoroughly also for relational data. Therefore, new data collection modes, such as Internet should also be comprehensively studied and evaluated against traditional data collection modes prior to their application to substantive topics.

Although Web surveys have already been used for a decade (see www.websm.org, a Web site dedicated to the methodology of Web surveys) they have very rarely been used for collecting data on ego-centred networks due to the complexity of the respondent's task. Beside our studies on this topic (the present study and the study described in Lozar Manfreda et al., 2004) we know of only few other studies assessing ego-centred network using a Web questionnaire. Two of them are Franzen (2002) and Nie and Erbring (2002) studies, however in these studies social networks were measured indirectly. Respondents were asked only about the size and time dedicated to social relationships, using a traditional survey questionnaire on the Web and not through name generators and name interpreters. Another study is the Marin (2002) study where a Web questionnaire was used to collect ego-centred network data. In this case a name generator and name interpreters were used, however this study did not discuss and evaluate the quality of data with respect to the Web-based administration.

Our study was designed to measure ego-centred social networks on the Internet using the direct approach (i.e. listing alters and evaluating characteristics of alters and measured ties) and to evaluate the usefulness of the Internet as a data collection mode. Web surveys had already proved to be a valid and reliable survey method for classic survey questionnaires (e.g., Clayton and Werking, 1998; Couper, 2000; Dillman, 2000; Bosnjak and Tuten, 2001; Couper et al., 2001; Lozar Manfreda, 2001; Vehovar et al., 2002). With our study we wanted to go further, i.e. to establish the usefulness of the Web survey mode when respondents are asked to perform more complex tasks such as those requested when measuring ego-centred social networks using name generators. In this sense, our study paid special attention to dropouts from the questionnaire, with respect to the number of listed alters and a question wording experiment. 


\section{Questionnaire specifics and advantages of Web- based administration}

It is complicated to manage a questionnaire collecting data regarding ego-centred networks. The questionnaire consists of several parts: one or more list of alters (name generators) and additional questions regarding these alters (name interpreters). Usually the list of alters is compiled and edited by interviewers in face-to-face interviews with the respondents - egos. The interviewer poses the name generator, while also makes and edits the list of alters. The interviewer's task is especially complicated if a paper-and-pencil questionnaire is used. He/she has to keep track of alters named in the name generator(s) and pose additional questions for each specific alter from the list.

Web questionnaires offer several opportunities for simplifying the process of such data collection. These opportunities can be contributed to two dimensions: computerisation of the questionnaire on one hand, and self-administration on the other hand.

The introduction of computerised questionnaires (either for interviewer- or self-administered questionnaires) has significantly reduced the interviewer's/respondent's burden. The software used in Web questionnaires can have an identical set of features simplifying the interviewer's or respondent's tasks as does CATI or CAPI software. The software itself remembers the alters, keeps track of which alters have already been filled in, and poses questions about the alters that are not yet completed. Here, the feature of using so called "adaptive questionnaires" (assigning questionnaire items based on earlier answers from the respondent) is applicable. The software remembers the text entry of the alter's name and uses it in subsequent questions regarding this alter.

The computer software thus simplifies the management of a long list of alters, a substantial task that is prone to interviewer (or respondent) error. In addition, computerisation offers certain opportunities for developing network questionnaires that would be harder to realise in paper-and-pencil questionnaires, for example, the opportunity to sample alters when administering name interpreters (in the event that a questionnaire needs to be shortened). Of course, data entering, processing, and database preparation is also built into the computer software.

The self-administration aspect of Web questionnaires adds certain specifics to the administration of network questionnaires, too. In this case it is the respondent who is responsible for compiling the list of alters. The names of these alters appear in the following stages of the questionnaire as variable names, and the respondent evaluates the characteristics of alters and ties. This is a very burdensome task for the respondent and it is virtually impossible to demand of him/her to perform it without using some type of a computerised questionnaire.

Despite the complex and burdensome task the respondents face in selfadministered questionnaires, there are certain indices suggesting that insisting on 
self-administration and not using interviewers would remove a certain level of measurement error. For example, it has been shown (Van Tilburg, 1998; Marsden, 2003 ) that the number of names given in response to name generators (thus the network size) is subject to interviewer effect. Thus, not using interviewers would improve network data by making the questionnaire more standardised across respondents. In addition, the absence of the interviewer in self-administered Web surveys may have a positive impact on the quality of data regarding sensitive and personal questions (Coomber, 1997; Aspinall et al., 2000: 237) such as questions on ego-centric social networks can sometimes be.

The other side of the above mentioned advantages due to computerisation and self-administration is that a great deal of work must be done in the preparation phase of the questionnaire before it can be placed on-line. The increased labour of programmers and interface designers substitutes that of interviewers and data processors. Pre-testing must be especially extensive in order to ensure that the instrument works well, given that interviewers are not present to troubleshoot problems. This is a necessity for any self-administered computerised questionnaire, but it is probably of particular importance for one that uses a complex instrument.

All of the above mentioned characteristics of Web questionnaires for measuring ego-centred social network data are not really specific to Web-based administration. They are characteristic also for other computerised or other selfadministered survey questionnaires. The specifics of Web questionnaires can be found in the combination of both dimensions (resulting in a computerised selfadministered questionnaire) strongly supported with a special channel capacity of the Web mode. Here, we mean the ways of presenting information to respondents that are not present in other survey modes, whether because they are not possible or are too expensive and time-consuming to develop and duplicate. Web survey instruments actually no longer consist only (or primarily) of verbal features (words and numbers) but can make use of rich visual features (Couper, 2001). These features include the use of multiple colours, special navigational features (e.g., indexes, tables of contents, progress indicators), still and moving images, animations, line drawings, sound, etc. These can be added to traditionally presented survey questions in order to illustrate them or simply to motivate the respondents (Lozar Manfreda et al., 2002).

In line with the above discussion of the specifics of the Web mode, a special issue that needs to be solved with the design of the Web questionnaire is the provision of text entry boxes for writing down the names (nicknames, shortened names) of alters. There are several dilemmas to solve in deciding what kind of approach is best suited. These include what form of wording would be clearest for the respondents, how many spaces should be provided for names and what should be the graphic outline of the name generator. Previous research on traditional survey modes has shown that a limitation in the number of alters given ultimately influences the size of social networks, and it has been suggested that the number 
of alters should not be limited (for example, Holland and Leinhardt, 1973; Zemljič and Hlebec 2003). However, when computer software is used, some limitations should be in place due to technical reasons (the number of available variables/fields should be limited). Any selected design is, therefore, a compromise between two criteria - providing enough space to get all relevant names and avoiding limitations, which could possibly result in a biased network size. This paper is actually mostly about this issue: how should the name generator in Web questionnaires be designed.

\section{Hypotheses}

The aim of our research is to test whether the Web can be used for collecting data with such complex questionnaires as the ones for collecting ego-centred network data. However, at this instance we are not interested in the quality of data as regards the sampling and coverage problem of Web surveys (Couper, 2000), but rather in the errors (measurement and non-response) which are a consequence of the measurement instrument, i.e. in our case the questionnaire design.

The characteristics and specifics of the questionnaire for collecting egocentred network data when respondents complete the questionnaire on the Web by themselves were presented in Section 2. We are interested in the effect of these characteristics. However, our study was not designed to assess the effect of the Web mode itself by comparing it to other modes (we did not gather data by any other mode, such as telephone or face-to-face interviews). Rather, it was designed to explore the effect of the present questionnaire design and a wording experiment within a single Web survey case.

In line with our intention the following hypotheses have been formulated:

1. The fact that the respondents complete the questionnaire by themselves introduces specific measurement errors that do not occur in intervieweradministered surveys. We expect that some respondents will fail to properly follow the instructions for writing in the names (nicknames, shortened names) of individual alters in the text boxes provided. For example, we expect them to write more than one name in one entry box, or to write "family" instead of individual names, etc.

2. The number of spaces (text boxes) provided for filling in the names of the alters introduces additional possible errors. We expect the respondents to be influenced to a greater extent by the visual design (by how many empty spaces they see on the screen) than by the wording of the question.

3. The greater effort put into the elaboration of the question wording for name generators positively affects the data quality. We expect respondents to make fewer errors if the wording is more specific and explicit. More precisely, if we specify that there will be additional questions posed for each listed alter, we expect respondents to name only the most important, 
and therefore fewer, alters. In addition, we expect lower item and partial non-response at name interpreters as the result of smaller number of alters.

4. The variation in question wording of the name generators introduces anomalies also within the substantive results. We expect some differences in network characteristics and the characteristics of ties in accordance with different instruction wording.

The first three hypotheses refer to the data quality obtained with a Web questionnaire in terms of the introduction of errors, such as non-valid answers and item and partial non-response. The fourth hypothesis, on the other hand, refers to the effects on substantive results.

The first two of these hypotheses are not specific to Web questionnaires only but would apply to any self-administered questionnaire. The third and the forth hypothesis are also not specific merely to Web questionnaires but are rather generic issues of network data collection. An effect question wording has on the results can actually be expected regardless of the mode. Nevertheless, we believe that our study contributes to the body of knowledge regarding the methodology of Web surveys and the methodology of collecting ego-centred network data. In addition, our findings can be valuable for all researchers, who would like to combine the two research lines and use the Web for collecting data on ego-centred social networks.

\section{Data: National RIS Web survey 2001}

The data for this study was gathered in 2001 through the annual national RIS Web survey of Internet users in Slovenia (within the project RIS - Research on Internet in Slovenia, Faculty of Social Sciences, University of Ljubljana; see www.ris.org). This was a self-selected Web survey of Internet users in Slovenia, which was advertised on all major Web sites in Slovenia (over 200 leading Web-sites placed a banner ad for the survey). Email invitations to the survey were also sent to addresses from the public e-mail directories in Slovenia $(20,000$ e-mail invitations). Over 14,000 responses to the 2001 survey were obtained in the period ranging from June to October 2001. This survey was a Web survey with general invitations, where no list of units was prepared prior to questionnaire completion (Lozar Manfreda, 2001: 12-46), i.e. a non-probability Web survey (Couper, 2000). Such Web surveys do not permit statistical inference and generalisation of substantive results to the general population, since respondents are self-selected with an unknown selection probability. However, since we are not interested in the survey errors of non-observation (sampling, coverage, and unit non-response), but rather in measurement errors, such a study can also give useful results. That is, despite their limitation in representativeness, non-probability, unrestricted, selfselected Web surveys can have (limited) value for scientific purposes; 
questionnaire design, questionnaire pre-testing, or psychological experiments and tests are often implemented within such surveys (Lozar Manfreda, 2001: 32-34).

\subsection{Questionnaire}

The Web questionnaire included a series of question modules on different survey topics. The first (compulsory) module included basic questions on Internet use, social-demographic questions, and questions on Web page visits. After that, subsamples of respondents were randomly (based on an ID number assigned when entering the questionnaire) administered one of the additional 13 modules. After answering an additional module, they were also asked to optionally select additional modules from the remaining list.

Questions about ego-centred social networks were included in the "Interpersonal relationships" module. Out of over 14,000 respondents to the RIS 2001 Web survey, 1,009 responded to the module on interpersonal relationships. $96 \%$ of them selected it by themselves, while merely $4 \%$ of the respondents were assigned it randomly by the software. 1,009 (mostly volunteer) respondents are therefore included in this analysis. These respondents were randomly split into four groups (again based on an ID number assigned when entering the questionnaire), and each received one name generator out of four name generators used to measure social support. When defining the types of social support provision, we relied on a typology given by Burt (1984) and Cohen and Wills (1985). They proposed four types of social support: instrumental, informational, emotional support and social companionship. The wording of the four network generators was therefore, as follows:

1. Instrumental support (small services): "From time to time people borrow something from other people, for instance, a small sum of money, or a piece of equipment, or ask for help with small jobs in or around the house. Who are the people you usually ask for this kind of help?";

2. Informational support (advice): "From time to time people ask other people for advice when a major change occurs in their life (for instance selecting a major, a job change or something similar). Who are the people you usually ask for advice when such a major change occurs in your life?";

3. Social companionship (socialising): "Sometimes you socialise with other people, for example, you visit them (or they visit you), or you take a trip together or go to dinner, movies, etc. Who are those people you usually socialise with?";

4. Emotional support (discussing important personal matters): "From time to time people discuss important personal matters with other people, for instance if they have problems at work, at school, with their partner or parents or in other similar situations. Who are the people with whom you discuss personal matters that are important to you?". 
As explained earlier, when asking questions in the form of name generators, we had to decide how many spaces for writing down the alters should be provided. We did not want to limit respondents by suggesting the number of alters (for example 3, 5 or 10 alters); therefore we provided 30 spaces, which seemed reasonably close to an unlimited option (see Figure 1). However, this design had an effect, as shown later, since it suggested respondents that numerous names are desirable. We therefore changed the wording of the question in the second phase of the survey (in September 2001), with the aim to reduce the effect of the graphic layout of the Web questionnaire. For the two wordings used, see Figure 2.

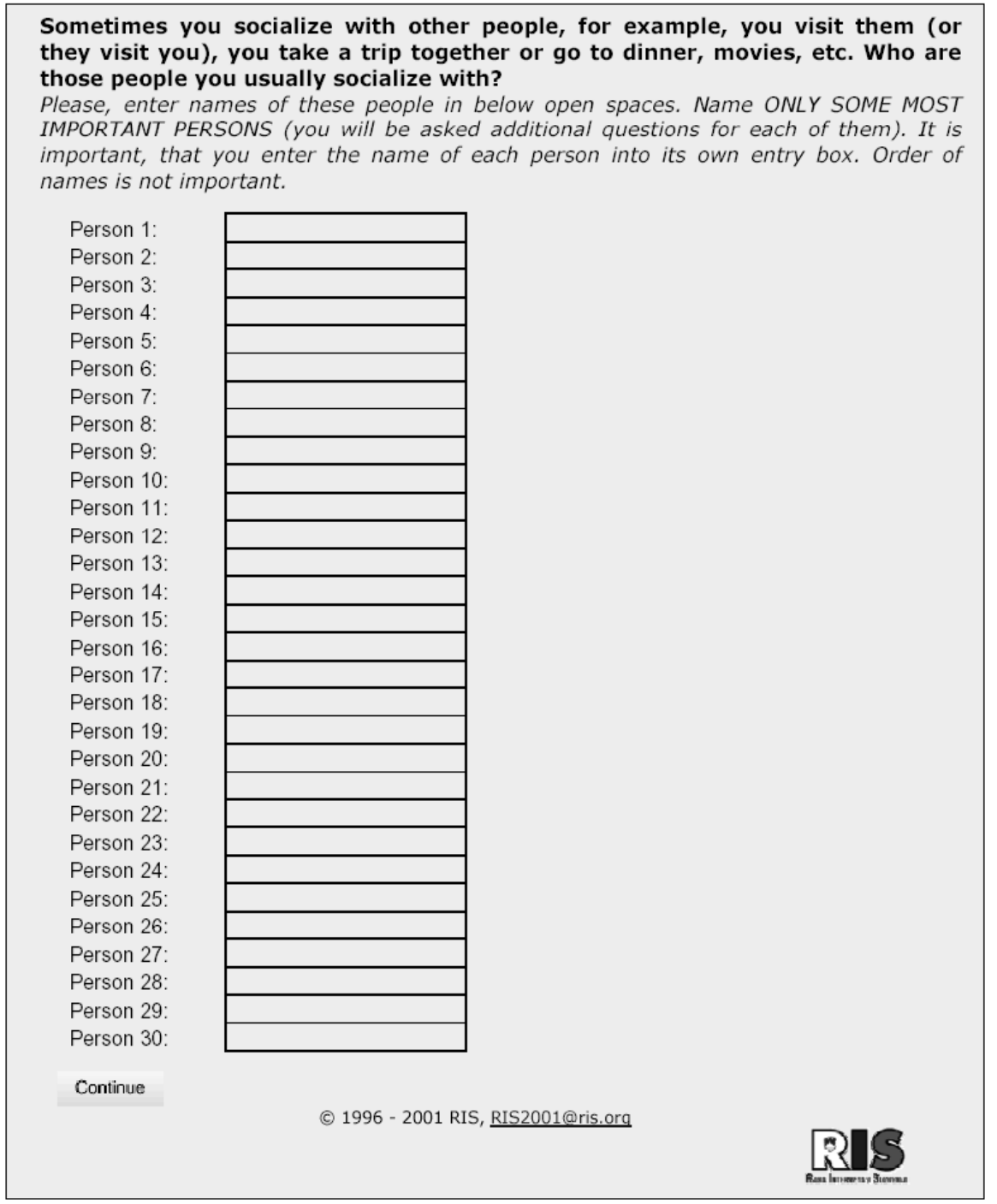

Figure 1: Layout of one the name generator pages of the Web questionnaire. 
Initial wording:

Sometimes you socialize with other people, for example, you visit them (or they visit you), you take a trip together or go to dinner, movies, etc. Who are these people you usually socialize with?

Please, enter the names of these people in below open spaces. You can name as many people as you want. It is important, that you enter the name of each person into its own entry box. Order of names is not important.

Changed wording in the second phase:

Sometimes you socialize with other people, for example, you visit them (or they visit you), you take a trip together or go to dinner, movies, etc. Who are these people you usually socialize with? Please, enter the names of these people in below open spaces. Name ONLY SOME MOST IMPORTANT PERSONS (you will be asked additional questions for each of them). It is important, that you enter the name of each person into its own entry box. Order of names is not important.

Figure 2: Introduction of experimental wording.

\subsection{Description of the sample}

Participants in this study constitute a convenience sample; they are very specific a convenience sample of Internet users who decided to participate in the national RIS 2001 Web survey after they had noticed banner ads for the survey on Slovenian Web sites, or after they had received the RIS e-mail invitation. In addition, they mostly chose to answer the questions on interpersonal relationships themselves. Nevertheless, despite their volunteer nature these 1,009 respondents do not differ much from the general population of Internet users in Slovenia as regards the social-demographic characteristics (see Table 1). A somewhat larger difference can be observed only as regards the percentage of men. While there is a higher percentage of men in the general population of Internet users, this percentage is somewhat lower in our sample. This has to do with how the respondents to the Interpersonal relationships module were selected from all of the respondents in the RIS Web survey. Since they could select it by themselves, it seems that this topic was more interesting to women than men.

In terms of Internet use, the participants in this study are more intensive Internet users - most of them using the Internet on a daily basis - in comparison to the general population of Internet users. This presents a certain limitation, since the results cannot be generalised to the general population of Internet users without caution. Nevertheless, some methodological implications can also be drawn from this study. 
Table 1: Comparison of social-demographic characteristics and frequency of Internet use among the participants in our study, and the general population of Internet users ${ }^{3}$.

\begin{tabular}{|l|c|c|}
\hline & $\begin{array}{c}\text { General population of } \\
\text { Internet users } \\
\boldsymbol{n = 2 5 7}\end{array}$ & $\begin{array}{c}\text { Participants in this } \\
\text { study } \\
\boldsymbol{n}=\mathbf{1 0 0 9}\end{array}$ \\
\hline \% men & $59 \%$ & $45 \%$ \\
\% with university education & $30 \%$ & $37 \%$ \\
Average age & 30 & 30 \\
$\%$ employed & $57 \%$ & $51 \%$ \\
$\%$ still attending school /faculty & $41 \%$ & $43 \%$ \\
$\%$ daily users & $47 \%$ & $85 \%$ \\
\hline
\end{tabular}

\section{Results}

\subsection{Problems with data quality due to questionnaire specifics (Hypotheses 1 and 2)}

Owing to the complex questionnaire structure and its self-administered character, considerable data cleaning was necessary before analysis could take place, especially in the list of alters. The software allowed any combination of strings to be written in the text boxes. Each was taken as a valid answer, and additional questions for alters were displayed for each of these 'names'. However, from the researcher's point of view, not all answers were valid, and additional data cleaning was necessary. If at least one character that was a letter appeared in the box where the name of an alter should have been written, we decided to accept this as the 'name' of an alter. The respondents were told that they could write in names, nicknames or shortened names. However, in some cases this procedure required some arbitrary decisions as regards the validity of the answers: e.g. - was " $a$ " or " $k v$ " actually meant as a name of an alter by the respondent, or not.

In addition to the problem with these short strings where we were unable to tell whether they had a meaning or not, some respondents did not fully comply to the instructions for writing in the names (or nicknames, or shortened names) of individual alters in the text boxes provided. They understood the instruction to write one name in each text box - there were no cases where a respondent listed more than one name in the provided text boxes. However, there were cases where respondents did not write names of individuals, but used more general expressions; for example, "me", "myself", "parents" (names in plural in general). Some did not write names at all, but provided answers such as "I do not borrow things", "don't want to answer", “P’, “...". Although for research purposes these are not valid answers, the computer software regarded all of these as valid. This

\footnotetext{
${ }^{3}$ Data for the general population of Internet users are taken from a RIS telephone survey on a representative sample of Slovenian households $(\mathrm{n}=901)$. This survey was conducted in June 2001 (see www.ris.org) and 257 Internet users were interviewed.
} 
caused severe frustrations for respondents who received additional questions for each of such 'alters', and to whom these questions made no sense. For example, there was a person who copied the answer "don't' want to answer" 30 times; he/she was, therefore, administered 30 pages of additional questions starting with "The following 11 questions regard the person you named 'don't want to answer'. How often are you in touch with this person?"

Fortunately, such cases were rare. The percentage of cases where only one letter was used as the name of an alter ranged from $1.4 \%$ to $0.1 \%$, depending on which alter we were asking for (this percentage was smaller for later alters). The percentage of cases where a non-valid answer was given ranges from $0.1 \%$ to $1.8 \%$ (depending on which alter we were asking for). All together, twelve respondents (out of 1009) gave non-valid answers for alters' names; therefore the number of respondents was reduced in the further analysis. Nevertheless, the problems with non-valid entries to the alter list resulted in frustration for respondents later on when asked additional questions about alters - and increased the number of dropouts from the survey, as discussed in Section 5.2.4.

The number of spaces (text boxes) provided for writing in the names of alters introduced additional errors. Some respondents were more influenced by the visual design (by how many empty spaces they saw on the screen) than by the wording of the question. There were 30 spaces provided on the screen; however the wording of the question did not ask for the names of 30 persons; it asked only for those to be named with whom the ego was in a certain relation (one of four social support provisions). As has been established, 30 spaces were provided because we did not want to limit the number of alters in any way. Such a design turned out to be a problem. Initial analysis performed already during the data collection phase showed that some respondents were heavily influenced by the visual design. They thus listed numerous, as many as 30 alters, although it is very unlikely that someone would have, for example 30 persons from whom they could borrow things. With the first wording of the question (see Section 4.1, Figure 2), there were actually 112 respondents (15\%) who named exactly 30 persons, although it is highly unlikely that their support network actually comprises 30 persons. The change in wording later on in the data collection process decreased the influence of the visual design, as will be explained in the next section.

\subsection{Results of the wording experiment (Hypotheses 3 and 4)}

\subsubsection{Weighting}

As has been already explained, we discovered that the respondents were heavily influenced by the visual design of the name generator, i.e. by the 30 spaces provided on screen during the data collection process. We therefore decided to 
change the wording of the question in order to decrease this effect (see Section 4.1, Figure 2). Since the wording was changed during the data collection phase, we do not have a randomised experiment. The group who received more precise detailed wording in the second phase of the data collection process is a group of more advanced Internet users - they use the Internet more often; there is a larger percentage of men, and they have higher education and are older (however they do not differ in their employment status). Nevertheless, we believe that the comparison of the two wordings is appropriate after we had made the two groups of respondents equal in terms of socio-demographic variable and frequency of Internet use (see Table 2). All further analysis in this section is thus performed on weighted data.

Table 2: Comparison of social-demographic characteristics and frequency of Internet use among the two 'experimental' groups.

\begin{tabular}{|c|c|c|c|c|c|c|}
\hline & $\begin{array}{c}\text { Before } \\
\text { weighting }\end{array}$ & & & $\begin{array}{c}\text { After } \\
\text { weighting }\end{array}$ & & \\
\hline & $\begin{array}{c}1^{\text {st }} \text { group: } \\
\text { Short } \\
\text { wording } \\
n=734\end{array}$ & $\begin{array}{c}2^{\text {nd }} \text { group: } \\
\text { Longer, } \\
\text { detailed } \\
\text { wording } \\
n=275\end{array}$ & $\begin{array}{c}\text { Stat. } \\
\text { sign. for } \\
\text { difference }\end{array}$ & $\begin{array}{c}1^{\text {st }} \text { group: } \\
\text { Short } \\
\text { wording } \\
n=734\end{array}$ & $\begin{array}{c}2^{\text {nd }} \text { group: } \\
\text { Longer, } \\
\text { detailed } \\
\text { wording } \\
n=275\end{array}$ & $\begin{array}{l}\text { Stat. sign. } \\
\text { for } \\
\text { difference }^{4}\end{array}$ \\
\hline$\%$ men & $41 \%$ & $55 \%$ & $p<0.0005$ & $45 \%$ & $44 \%$ & $\mathrm{p}=0.805$ \\
\hline $\begin{array}{l}\% \text { with university } \\
\text { education }\end{array}$ & $33 \%$ & $49 \%$ & $\mathrm{p}<0.0005$ & $37 \%$ & $40 \%$ & $\mathrm{p}=0.404$ \\
\hline Average age & 29 & 31 & $\mathrm{p}=0.002$ & 29.1 & 30.4 & $\mathrm{p}=0.094$ \\
\hline$\%$ employed & $50 \%$ & $53 \%$ & $\mathrm{p}=0.490$ & $51 \%$ & $52 \%$ & $\mathrm{p}=0.916$ \\
\hline $\begin{array}{l}\% \text { still attending } \\
\text { school /faculty }\end{array}$ & $43 \%$ & $41 \%$ & $\mathrm{p}=0.596$ & $43 \%$ & $42 \%$ & $\mathrm{p}=0.890$ \\
\hline$\%$ daily users & $83 \%$ & $89 \%$ & $\mathrm{p}=0.027$ & $85 \%$ & $85 \%$ & $\mathrm{p}=0.925$ \\
\hline
\end{tabular}

\subsection{2 “Design" vs. substantive answers}

We believe that those respondents who listed exactly 30 alters were heavily influenced by the visual design of the question and that their respective network size is not as high as 30. This can be clearly seen from Figure 3; most respondents named between 3 and 10 alters, and the share of those listing more than 10 alters decreases gradually. The share rises again at 30 alters, showing that there was a significant segment of respondents who were influenced by the visual design of the question. If this was not the case, we should have an equal share of respondents distributed across the higher numbers of alters. We can therefore conclude that we have respondents who gave "design" answers (exactly 30 names) and who should be distinguished from those giving substantive answers.

\footnotetext{
${ }^{4}$ Chi square test used for nominals and t test for ratio (age).
} 


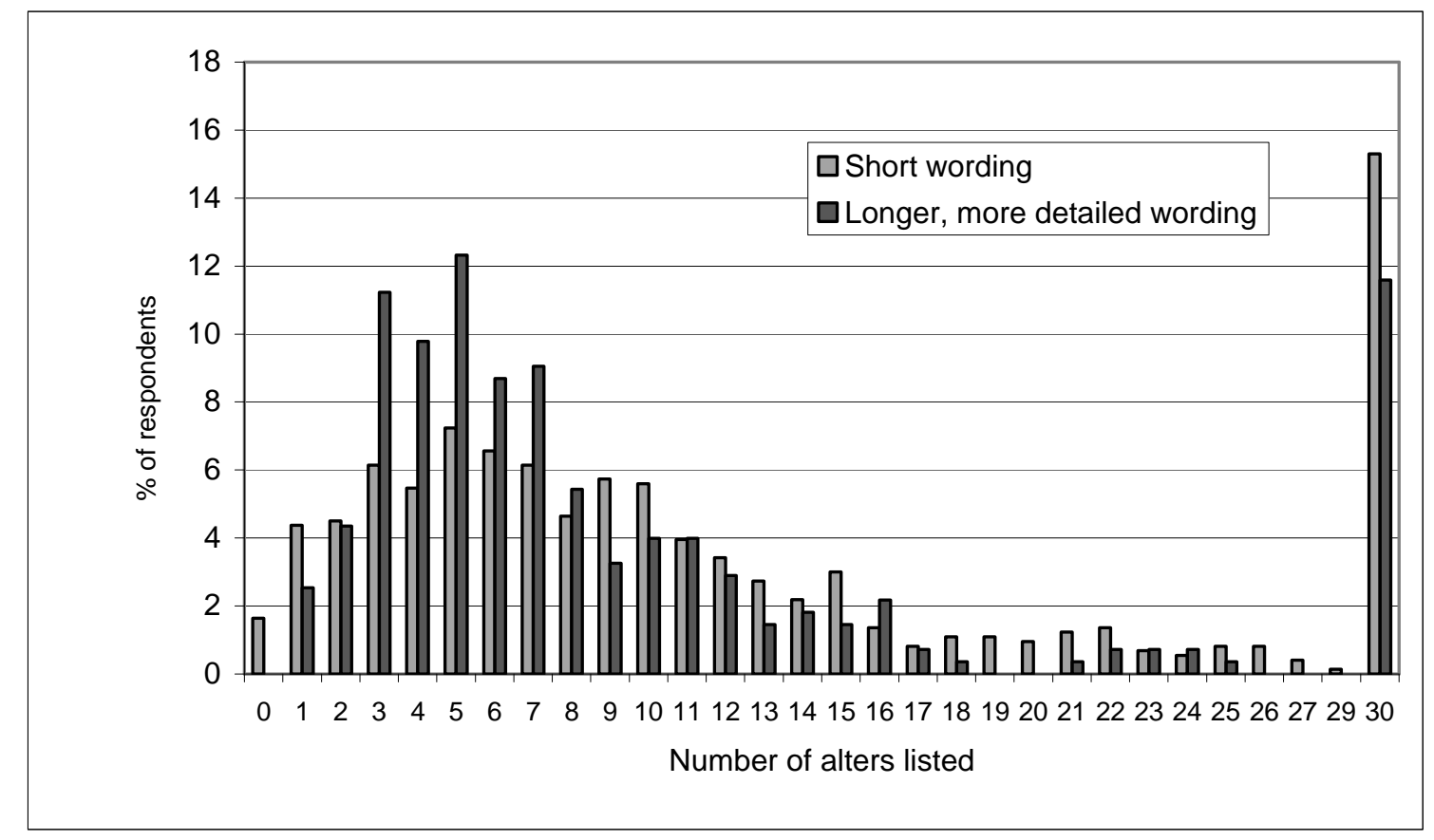

Figure 3: $\%$ of respondents listing a certain number of alters with regards to the wording experiment (overall, across all name generators).

Table 3: Characteristics of respondents with "design" answers.

\begin{tabular}{|l|c|c|c|}
\hline & $\begin{array}{c}\text { Respondents with } \\
\text { “design” } \\
\text { answers }\end{array}$ & $\begin{array}{c}\text { Respondents with } \\
\text { substantive answers }\end{array}$ & $\begin{array}{c}\text { Statistical } \\
\text { significance } \\
\text { (chi square or } \\
\text { t-test) }\end{array}$ \\
\hline \% men & $47 \%$ & $44 \%$ & $\mathrm{p}=0.495$ \\
\% with university education & $40 \%$ & $38 \%$ & $\mathrm{p}=0.617$ \\
Average age & 29.6 & 29.5 & $\mathrm{p}=0.902$ \\
$\%$ employed & $54 \%$ & $51 \%$ & $\mathrm{p}=0.685$ \\
$\%$ still attending school/faculty & $40 \%$ & $43 \%$ & $\mathrm{p}=0.654$ \\
$\%$ daily users & $86 \%$ & $85 \%$ & $\mathrm{p}=0.642$ \\
\hline
\end{tabular}

In searching for reasons why some respondents were highly influenced by the visual design of the question in describing their social support network, we compared the socio-demographic characteristics and frequency of Internet use of respondents with "design" answers to those of respondents with substantive answers (Table 3). However, there is no difference between the groups in terms of the selected variables. Based on demographic characteristics or frequency of Internet use, we cannot predict which respondents would be more influenced by the visual design. 


\subsubsection{Effect of wording on the average network size}

In Table 4 we can observe the effect of the change in wording on the network size. Overall (across all name generators), the percentage of respondents who named exactly 30 alters is $16 \%$ in the shorter version and $12 \%$ in the longer, more precise version of the question. However this difference is not statistically significant $(\mathrm{p}=0.118)$. The same pattern is observed if individual name generators are taken into account. On the other hand, there is a statistically significant reduction in the average network size following the change in wording. If we look at all of the respondents, we can see that the overall network size (across all name generators) is 12.1 persons for the shorter version and 9.8 persons for the longer, more precise version $(\mathrm{p}<0.0005)$ (see Table 5). There is some variation across different network generators; a statistically significant decrease in the average network size is actually characteristic only for instrumental support and socialising, although the decrease is seen for all generators.

Table 4: \% of respondents with "design" answers.

\begin{tabular}{|l|c|c|c|}
\hline & \multicolumn{3}{|c|}{$\%$ of respondents with 30 alters named } \\
\hline Name generator & $\begin{array}{l}\text { Short } \\
\text { wording }\end{array}$ & $\begin{array}{l}\text { Longer, } \\
\text { more detailed } \\
\text { wording }\end{array}$ & $\begin{array}{l}\text { Statistical significance for } \\
\text { difference (chi square) }\end{array}$ \\
\hline Instrumental support $n=254$ & $15 \%$ & $7 \%$ & $\mathrm{p}=0.106$ \\
Informational support $=253$ & $5 \%$ & $2 \%$ & $\mathrm{p}=0.298$ \\
Socialising $n=236$ & $33 \%$ & $23 \%$ & $\mathrm{p}=0.118$ \\
Emotional support $n=254$ & $13 \%$ & $10 \%$ & $\mathrm{p}=0.516$ \\
\hline Overall $n=997$ & $16 \%$ & $12 \%$ & $\mathrm{p}=0.118$ \\
\hline
\end{tabular}

When we exclude the respondents with "design" answers (i.e., those who listed exactly 30 alters - see Table 5) from the analysis, the average network size is, of course, reduced, regardless of the wording (from 12.1 to 9.0 for the shorter wording and from 9.8 to 7.2 for the longer wording, across all name generators). However, the effect of wording is, overall (across all name generators), still significant: 9.0 persons for the shorter version vs. 7.2 persons for the longer, more precise version. The pattern across individual name generators is the same as in the previous case, with all showing reductions in network size with the more detailed wording; however a statistically significant reduction appeared only for instrumental support and socialising.

\subsubsection{Effect of the wording on the drop-out from the survey}

When substantive analysis is performed, such as the analysis of the support network composition or structure, information about alters is required. Therefore, it is not enough merely to obtain the list of alters' names; one also has to obtain data on these alters by completing the name interpreters. Owing to the self- 
administered data collection mode and to the fact that the generous space provided for listing names resulted in a large number of names, obtaining information about alters presented a problem. When an interviewer is present, the dynamics of the interview ensures nearly complete response even for name interpreters. On the other hand, in our case respondents tended to name many alters, and no interviewer was present to ensure answers to name interpreters. Thus further substantive analysis had to be performed on significantly fewer alters. Respondents tended to quit the questionnaire prematurely, before answering all name interpreters assigned to them.

Table 5: Network size as estimated from name generators.

\begin{tabular}{|c|c|c|c|}
\hline & \multicolumn{3}{|c|}{ Average number of alters named } \\
\hline & \multicolumn{3}{|c|}{ ALL RESPONDENTS INCLUDED } \\
\hline Name generator & $\begin{array}{l}\text { Short } \\
\text { wording }\end{array}$ & $\begin{array}{l}\text { Longer, more detaile } \\
\text { wording }\end{array}$ & $\begin{array}{l}\text { Statistical significance } \\
\text { for difference }(\text { t test })\end{array}$ \\
\hline Instrumental support $n=254$ & 11.6 & 8.1 & $\mathrm{p}=0.002$ \\
\hline Informational support $n=253$ & 8.0 & 7.0 & $\mathrm{p}=0.291$ \\
\hline Socialising $n=236$ & 19.9 & 14.1 & $\mathrm{p}<0.0005$ \\
\hline Emotional support $n=254$ & 10.3 & 8.9 & $\mathrm{p}=0.246$ \\
\hline \multirow[t]{2}{*}{ Overall $n=997$} & 12.1 & 9.8 & $\mathrm{p}<0.0005$ \\
\hline & \multicolumn{3}{|c|}{$\begin{array}{l}\text { RESPONDENTS WITH } \\
\text { EXCLUDED }\end{array}$} \\
\hline Name generator & $\begin{array}{l}\text { Short } \\
\text { wording }\end{array}$ & $\begin{array}{l}\text { Longer, } \quad \text { mor } \\
\text { detailed wordin }\end{array}$ & $\begin{array}{l}\text { Statistical significance } \\
\text { for difference }(t \text { test })\end{array}$ \\
\hline Instrumental support $n=222$ & 8.9 & 6.4 & $\mathrm{p}<0.0005$ \\
\hline Informational support $n=242$ & 7.0 & 6.4 & $\mathrm{p}=0.371$ \\
\hline Socialising $n=165$ & 14.9 & 9.4 & $\mathrm{p}<0.0005$ \\
\hline Emotional support $n=224$ & 7.6 & 6.5 & $\mathrm{p}=0.101$ \\
\hline Overall $n=852$ & 9.0 & 7.2 & $\mathrm{p}<0.0005$ \\
\hline
\end{tabular}

In an ideal situation, respondents would provide additional information for each alter they named in the name generator (see the line for ideal situation in Figure 4). However, this was not the case. Respondents mostly completed ${ }^{5}$ the additional questions regarding all alters if they named up to 5 alters. If they named more then 5 alters, they did not answer all the additional screens. The number of additional screens - name interpreters - answered decreases along with the increase in the number of named alters. For example, respondents who listed 15 alters, on average answered additional questions for only 11 of them ${ }^{6}$.

\footnotetext{
${ }^{5}$ By completed name interpreters, we mean those where at least one of the additional questions for a certain alter was answered. Taking into account only those who answered all additional questions for a certain alter, the network sizes for substantive analysis would be further significantly reduced.

${ }^{6}$ There is no difference across different name generators; therefore only overall data is presented.
} 


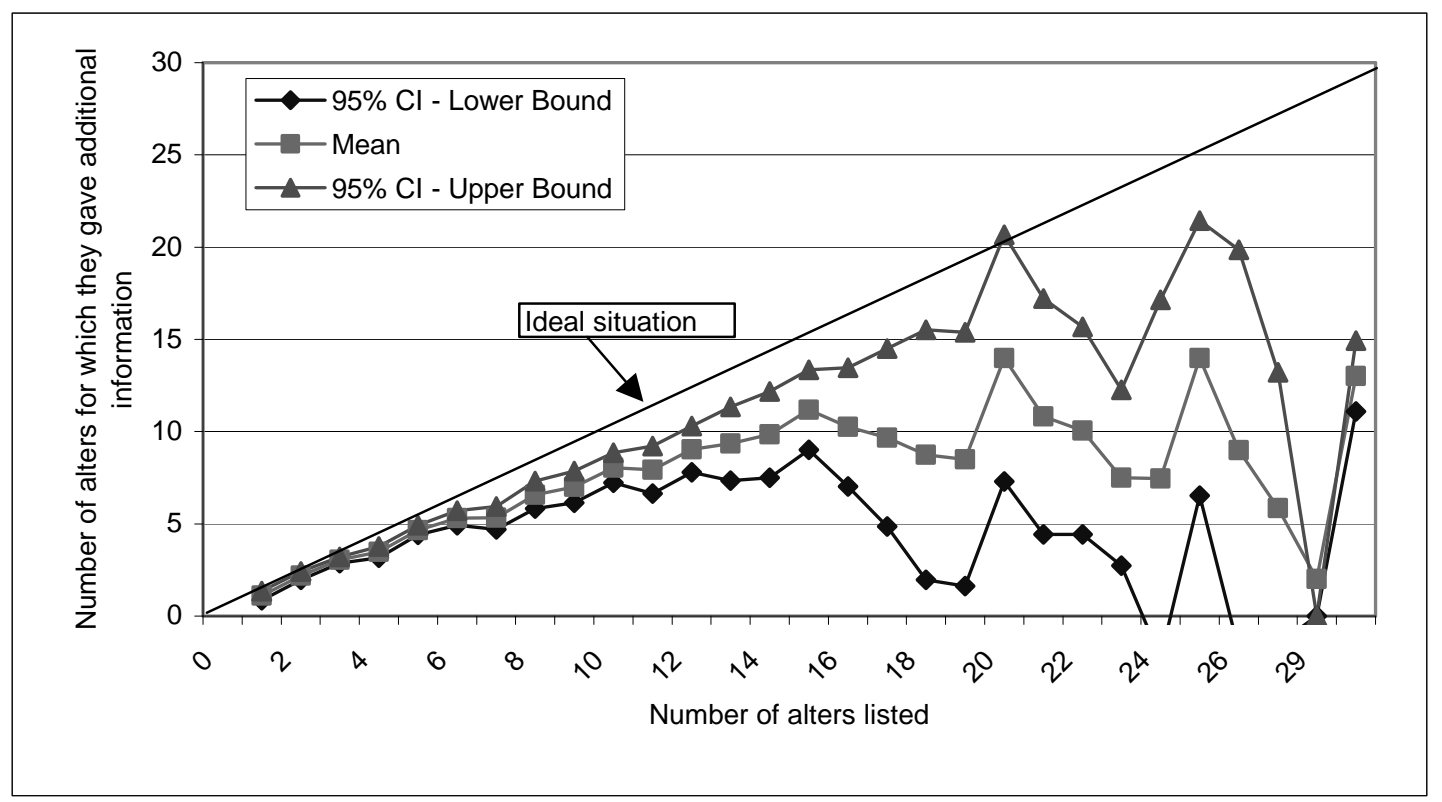

Figure 4: Average number of completed name interpreters ${ }^{7}$.

The change in wording had some effect on the completeness of the provided data. It not only reduced the network size, but also increased the number of completed name interpreters.

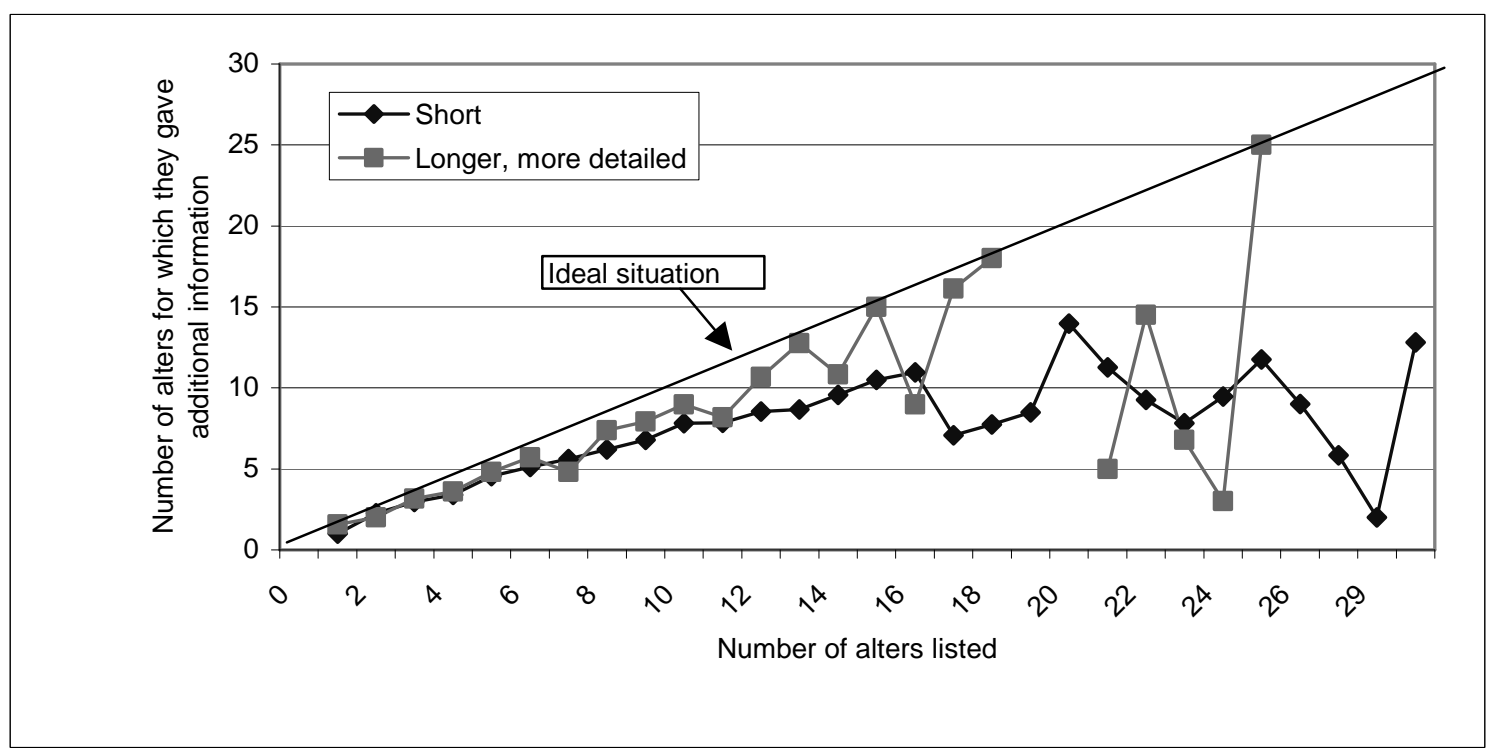

Figure 5: Average number of completed name interpreters with regards to the wording experiment $^{8}$.

\footnotetext{
${ }^{7}$ Due to the small sample size the analysis for more than 15 alters is only informative.

${ }^{8}$ Due to the small sample size the analysis for more than 15 alters is only informative.
} 
Quitting the questionnaire thus further reduces the network size for substantive analysis. Network size is thus reduced when only those alters for whom at least some data is obtained in name interpreters are taken into account. In our case substantive analysis is actually performed on networks of an average size of 7.0 (instead of 11.5). There is some difference in this reduced network size depending on the wording (7.1 for shorter and 6.8 for longer wording); however the difference is not statistically significant $(\mathrm{p}=0.619)$.

\subsubsection{Effects in substantive results}

The above analysis was oriented towards the implications of the specifics of the Web questionnaire (especially the wording experiment) for the data quality from a methodological point of view (validation of responses, non-response, etc.). In this section we will explore the implications for the substantive results. As researchers interested in people's social support networks, we explore variations in network size, the composition and characteristics of ties as a result of various factors. We show how these change according to the type of social support (type of name generator), wording experiment (short vs. long wording), Internet use (daily vs. not daily), gender (male, female), education and age.

The evaluation of the wording experiment was thus completed by the analysis of characteristics of ties among the respondents and their alters (duration of ties, geographical distance, closeness, importance; multiplexity of ties) and the composition of support networks (proportions of kin, friends, and co-workers among the listed alters). The variation in the estimated characteristics of ties and network composition was evaluated with several factors, using $\mathrm{MCA}^{9}$. The predictor variables were as follows: type of social support (type of name generator), wording experiment (short vs. long wording), Internet use (daily vs. not daily), gender (male, female), education and age (due to the interaction between the two variables a joint variable ${ }^{10}$ measuring education and age was introduced).

${ }^{9}$ Since all network measures are numerical variables and variables describing the type of network generator, the wording instruction and characteristics of the respondents were measured as nominal or ordinal variables. Multiple Classification Analysis (MCA) was chosen for analysis since it allows for nominal predictor variables and numerical dependent variable (Andrews et al., 1973). The multivariate (MCA) coefficients indicate to what extent does the estimate of network composition and characteristics of ties deviate from the mean as a result of a given characteristic of the measurement instrument (e.g. short wording) or demographic characteristics (e.g. frequency of Internet use), while controlling for the effects of all other characteristics of the measurement instrument. Two measures of the overall effect of each predictor are obtained, as well as the MCA Eta and MCA Beta coefficients. The MCA Eta coefficient measures the strength of the bivariate relationship between a network composition estimate and a predictor. On the other hand, MCA Beta coefficients measure the strength of the relationship, controlled for the other predictor variables in the model. The rank order of the Betas indicates the relative importance of the predictor variables in their explanation of the dependent variable. Finally, the multiple $\mathrm{R}^{2}$, indicating the total proportion of variance explained by all predictors together, is estimated.

${ }^{10}$ Values of the joint variable are: 
Table 6: Multivariate analysis for network size, proportion of kin, friends, co-workers and neighbours.

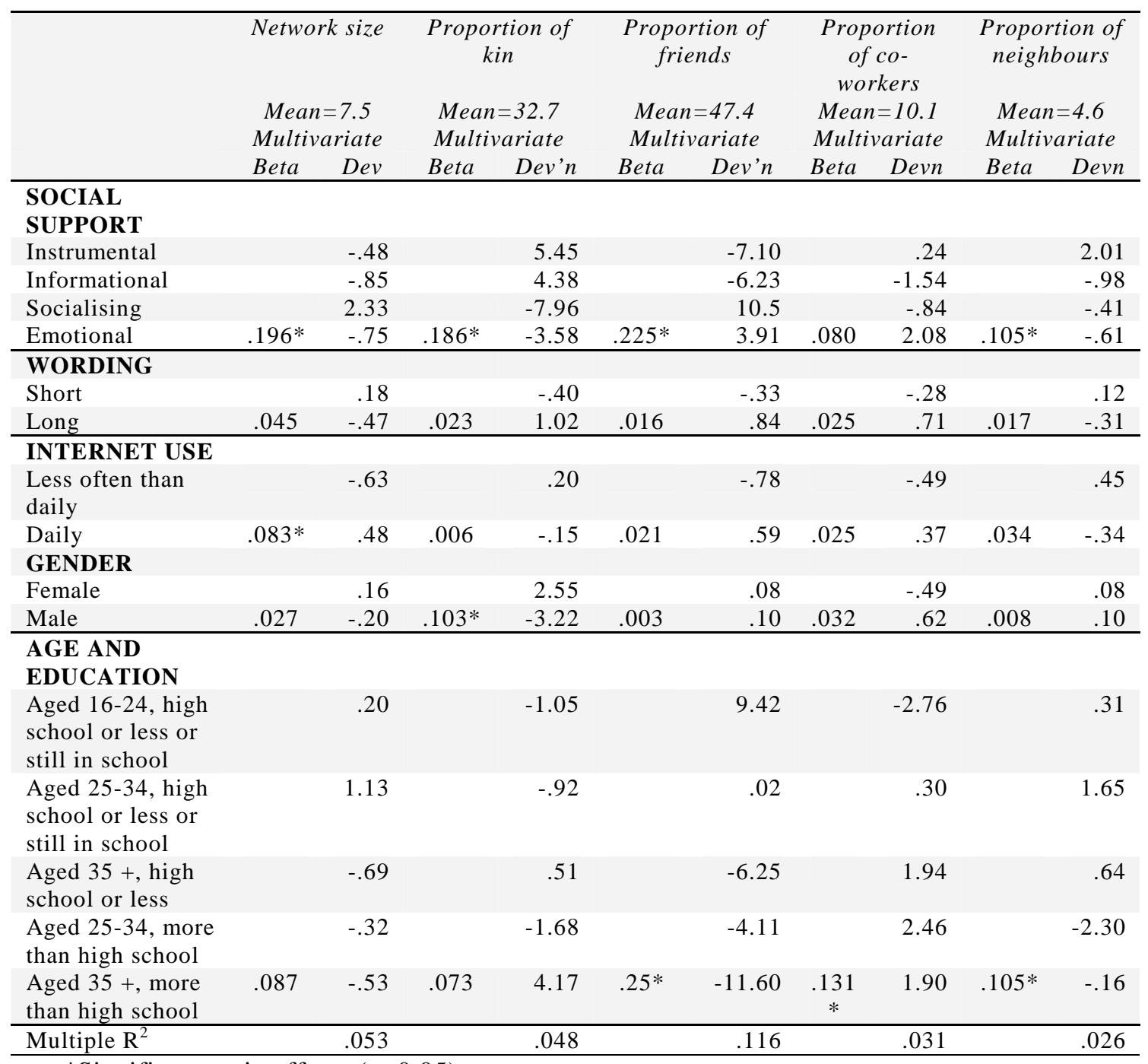

*Significant main effects $(\mathrm{p}<0.05)$.

Since the characteristics of evaluated ties and the composition of the four types of networks have been presented in detail elsewhere (see Hlebec et al., 2002), and several measures are evaluated, only the most important outcomes of MCA analyses are presented (see Table 6 and Table 7). Multivariate Beta coefficients show the relative importance of each predictor variable (significant predictors at $\mathrm{p}<0.005$ are labelled $*$ ). Our primary interest lies in the effect of the wording experiment. Betas are insignificant for all selected indicators of network composition and characteristics of ties. This indicates that network measures are

- $\quad 1$ - aged 16-24, with high school or less or still in school,

- 2 - aged 25-34, with high school or less or still in school,

- $\quad 3$ - aged 35 and over, with high school or less or still in school,

- 4 - aged 25-34 with more than high school,

- 5 - aged 35 and over, with more than high school. 
stable with regard to the wording experiment. It seems that both wordings produce networks of similar characteristics. Therefore the longer wording (which explicitly told respondents what was expected of them) is favourable, because of its lower dropout rate. One would thus suggest using detailed instructions in future Internet surveys. Nevertheless, there is some variation in network measures between the two wording instructions. Longer and more detailed wording produces smaller networks, with smaller proportions of kin, neighbours, women and alters living within 15-30 minutes drive by car, and larger proportions of friends, co-workers, and men, ties that are on average more close.

Table 7: Multivariate analysis for closeness, average number of years of acquaintance, proportion of female and male alters, and geographical distance (percentage of alters

living between 15-30 minutes away).

\begin{tabular}{|c|c|c|c|c|c|c|c|c|c|c|}
\hline & \multicolumn{2}{|c|}{$\begin{array}{c}\text { Closeness } \\
\text { Mean=3.9 } \\
\text { Multivariate }\end{array}$} & \multicolumn{2}{|c|}{$\begin{array}{c}\text { Acquain- } \\
\text { tance } \\
\text { Mean=14.2 } \\
\text { Multivariate }\end{array}$} & \multicolumn{2}{|c|}{$\begin{array}{l}\text { Proportion of } \\
\text { female } \\
\text { Mean }=56.6 \\
\text { Multivariate }\end{array}$} & \multicolumn{2}{|c|}{$\begin{array}{l}\text { Proportion of } \\
\text { male } \\
\text { Mean }=43.3 \\
\text { Multivariate }\end{array}$} & \multicolumn{2}{|c|}{$\begin{array}{c}\text { Geographical } \\
\text { distance } \\
\text { Mean }=50.7 \\
\text { Multivariate }\end{array}$} \\
\hline & Beta & Dev'n & Beta & $D e v$ & Beta & Dev'n & Beta & Dev & Beta & $D e v$ \\
\hline \multicolumn{11}{|l|}{ SOCIAL } \\
\hline Instrumental & & -.003 & & 1.10 & & -2.21 & & 2.21 & & 3.48 \\
\hline Informational & & .162 & & .96 & & -.42 & & .42 & & -6.96 \\
\hline Socialising & & -.267 & & -1.81 & & -1.04 & & 1.04 & & 6.33 \\
\hline Emotional & $.227 *$ & .080 & $.139 *$ & -.41 & $.087 *$ & 3.51 & $.087 *$ & -3.51 & $.17 *$ & -2.07 \\
\hline \multicolumn{11}{|l|}{ WORDING } \\
\hline Short & & -.015 & & -.00 & & -.20 & & .20 & & .63 \\
\hline Long & .032 & .038 & .001 & .01 & .013 & .53 & .013 & -.53 & .033 & -1.62 \\
\hline \multicolumn{11}{|l|}{ INTERNET USE } \\
\hline $\begin{array}{l}\text { Less often than } \\
\text { daily }\end{array}$ & & -.035 & & -.23 & & 2.04 & & -2.04 & & -.60 \\
\hline Daily & .044 & .027 & .024 & .17 & $.072 *$ & -1.56 & $.072 *$ & 1.56 & .017 & .45 \\
\hline \multicolumn{11}{|l|}{ GENDER } \\
\hline Female & & .057 & & .61 & & 6.15 & & -6.15 & & -.61 \\
\hline Male & $.093 *$ & -.073 & $.083 *$ & -.79 & $.281 *$ & -7.94 & $.281 *$ & 7.94 & .023 & .78 \\
\hline \multicolumn{11}{|l|}{$\begin{array}{l}\text { AGE AND } \\
\text { EDUCATION }\end{array}$} \\
\hline $\begin{array}{l}\text { Aged } 16-24, \text { high } \\
\text { school or less or } \\
\text { still in school }\end{array}$ & & -.055 & & -4.0 & & -.08 & & .08 & & .29 \\
\hline $\begin{array}{l}\text { Aged } 25-34, \text { high } \\
\text { school or less or } \\
\text { still in school }\end{array}$ & & -.080 & & -1.14 & & -1.54 & & 1.54 & & 1.76 \\
\hline $\begin{array}{l}\text { Aged } 35+\text {, high } \\
\text { school or less }\end{array}$ & & -.056 & & 4.06 & & 1.05 & & -1.05 & & 1.83 \\
\hline $\begin{array}{l}\text { Aged 25-34, more } \\
\text { than high school }\end{array}$ & & .012 & & -1.32 & & .46 & & -.46 & & -.99 \\
\hline $\begin{array}{l}\text { Aged } 35+\text {, more } \\
\text { than high school }\end{array}$ & $.119^{*}$ & .098 & $.530 *$ & 7.77 & .029 & .226 & .029 & -.23 & .046 & -2.28 \\
\hline Multiple $\mathrm{R}^{2}$ & & .076 & & .303 & & .101 & & .101 & & .031 \\
\hline
\end{tabular}

*Significant main effects $(\mathrm{p}<0.05)$.

Among other predictor variables, the type of name generator appears to be the most important one (significant main effects for all network measures except for proportion of neighbours), followed by gender (significant main effects for the 
proportion of kin, closeness, average number of years of acquaintance, proportion of female or male alters), age and education (significant main effects for proportion of friends, co-workers and neighbours, closeness, and average number of years of acquaintance), and frequency of Internet use (significant main effects for network size, and proportion of females or males).

Only the main effects were taken into account in these tables. However, there were some higher order interactions with experimental wording and other predictor variables:

Network size: second order interaction with frequency of Internet use (there were more daily users reporting larger networks with the longer wording instruction which produced smaller networks).

Proportion of neighbours: second order interaction with frequency of Internet use (there were more daily users with the longer wording instruction - both conditions are related to a smaller proportion of neighbours).

Closeness: second order interaction with frequency of Internet use (there were more daily users with the longer wording instruction - both conditions are related to ties of stronger closeness on average), and third order interaction with frequency of Internet use and gender (there was a smaller proportion of women with the longer wording instructions - women reported stronger closeness on average with their alters).

Average number of years of acquaintance: third order interaction with frequency of Internet use and the joint variable assessing age and education (there is smaller proportion of the youngest respondents with less education and a larger proportion of older and the oldest respondents with higher education with the longer wording instruction and daily Internet users) - daily users and younger respondents have known their alters on average for shorter periods. Nevertheless, these high-order interactions are not related to substantive changes in network composition owing to the wording experiment, but to the non-randomised experimental design.

\section{Discussion and conclusions}

This paper presents a trial in measuring ego-centred social networks with a Web questionnaire. Collecting survey data via Web questionnaires has already become an important mode in the survey industry, although usually only traditional survey questionnaires are used. There were very few trials in measuring ego-centred social networks, which require a rather complicated questionnaire design. Therefore, the value of such research is already resident in its pioneering status. However, as always with initial trials in any research field, we faced certain basic problems. Designing a Web questionnaire including name generators and interpreters was a demanding task. During the data collection process, we discovered that the visual design of our name generator was misleading: respondents were more influenced by the number of visible, on-screen spaces for 
entering alters' names than by what they read in the instructions. What they saw prevailed over what they read (or should have read). This had implications for further questionnaire completion, since respondents became frustrated with the resulting longer questionnaire and quitted the questionnaire prematurely.

An additional problem that occurred is related to the absence of an interviewer's presence who could ensure that respondents understood the instructions correctly, followed them and completed the questionnaire.

Based on our experience, we would suggest the following ways to improve the Web questionnaires for collecting ego-centred social network data:

1. Like in every questionnaire design process there is a special need for careful pre-testing of the Web questionnaire before the start of the study. This is even more important in self-administered surveys where the questionnaire is completed by the respondents themselves and there is no interviewer who would resolve the misunderstandings and motivate the respondents. In addition, this is especially important when the instrument is as complex as it is in the case of measuring ego-centred social networks.

2. Special attention needs to be given to the visual design of the questionnaire. On the Web, but also in every other self-administered questionnaire, respondents are more influenced by what they see than by what they read or should read. Therefore the visual design itself should be sufficiently clear. Any additional text should be formulated precisely, and the most important parts stressed by the use of visual stimuli (e.g., bold text, larger font, etc.). An alternative to our design where a name generator with 30 spaces was provided would be a design with 5 or 10 spaces on the first questionnaire screen. The respondents could be instructed to type in the names until they have listed everyone they want to list. At the bottom of the first screen there could be a question asking, whether there is a need for further space for listing names. If "Yes", a new screen would show up that would allow them to add additional names. These steps could be continued until the respondent would not wish to add any more names. An experiment aimed at finding the effect of providing space for 3, 5, or 10 alters was actually already performed (Lozar Manfreda et al., 2004) and the results regarding the improved quality of data are promising.

3. The used software should check the answers entered under alters' name during the completion of the first part of the questionnaire and exclude specific answers that occur most often, but are not valid (such as "no other", "/", etc.). In most cases, researchers can predict at least the majority of such non-valid answers that can be eliminated during questionnaire completion. This would spare much frustration to respondents and therefore contribute to a lower drop-out rate.

4. Another solution to the problem of non-valid answers to the name generator would be a software solution that would process the list of names and present it to the respondents for confirmation before the administration 
of name interpreters begins. Such a "confirmation screen" would allow respondents to remove names that are not individual persons (say by check boxes beside the entries) and to add additional names if they desired.

5. The instructions for the respondents should be detailed in explaining the respondents' task and what can be expected in the later parts of the questionnaire.

6. The number of name interpreters should be substantially reduced to ease the respondents' burden. Such a reduction in the number of name interpreters should be based either on a smart statistical procedure, or on substantive reasoning. One possible solution would be to request name interpreters only for a sample of users (already tested in Fisher, 1982) which is rather simply administered in computer-assisted questionnaires such as Web questionnaires.

There are several additional issues that have not been addressed in this paper, but are important when measuring data on ego-centred social networks, for example, the need to use several name generators within one questionnaire. In our case we used only one name generator; however, several name generators are very often needed. The wording and the visual design of the questionnaire should instruct the respondents to use the same name for alters that appear on several occasions, since an interviewer is not present. Further research is thus needed to explore what would be the best questionnaire design in order to achieve this goal.

In our study we did not deal in detail with the impact the respondents' Internet experience has on the results. We could expect that Web data collection may work better for experienced than inexperienced users. However, with our study we cannot explore such a hypothesis. Namely, the respondents to our survey were mostly very intensive Internet users (85\% of them using the Internet daily) thus there is not enough variation in experience to assess its impact on the results. In addition, there may be other variables that may affect the respondents' performance, for example, their motivation, mood, the place and time of answering the questionnaire, etc. For this study we are not able to assess such factors, however they are worthwhile of further research.

To summarise, our study was designed as a first trial to test whether such complex, demanding, long, and therefore burdensome questionnaires can be efficiently used in Web-based surveys. The first drawback that comes into mind is the fact that the questionnaire is self-administered, therefore there are no interviewers who could provide additional instructions, solve the misunderstandings and raise the motivation. On the other hand, the capacity of the Web software gives opportunities for a questionnaire design that could overcome this limitation. Our questionnaire design turned out not to be perfect for this purpose and based on our experiences suggestions for further research are given. 


\section{Acknowledgement}

We want to thank the anonymous reviewer for his/her detailed review and suggestions for improving this paper which were incorporated into the text. In addition, his/her insightful ideas give us further motivation to continue our work on methodology of network data collection using Web questionnaires.

\section{References}

[1] Andrews, F.M., Morgan, J.N., Sonquist, J.A., and Klem L. (1973): Multiple classification analysis. Michigan: The University of Michigan.

[2] Aspinall, E., Batey, R., and Branthwaite, A. (2000): What gets through the Net? Net use in brand communication and research. In The Worldwide Internet Conference Net Effects 3, Dublin (Ireland), 10-12 April 2000. ESOMAR Publication Series, 237, 229-245.

[3] Bernard, R.H., et al. (1990): Comparing four different methods for measuring personal social networks. Social Networks, 12, 179-215.

[4] Bernard, R.H., Shelley, G.A., and Killworth, P.D. (1987): How much of a network does the GSS and RSW dredge up? Social Networks, 9, 49-61.

[5] Bien, W., Marbach, J., and Neyer, F. (1991): Using egocentered networks in survey research. A methodological preview on an application of social network analysis in the area of family research. Social Networks, 13, 75-90.

[6] Bosnjak, M. and Tuten, T.L. (2001): Classifying response behaviors in Webbased surveys. Journal of Computer Mediated Communication, 6, 3. http://www.ascusc.org/jcmc/vol6/issue3/boznjak.html

[7] Brewer, D.D. and Webster, C.M. (1997): Recall and recognition of friends by residents of a university dormitory. Paper presented at the International Sunbelt Social Networks Conference, San Diego, USA.

[8] Burt, R.S. (1984): Network items and the General Social Survey. Social Networks, 6, 293-339.

[9] Burt, R.S. (1986): A note on sociometric order in the General Social Survey network data. Social Networks, 8, 149-174.

[10] Campbell, K.E. and Lee, A.L. (1991): Name generators in surveys of personal networks. Social Networks, 13, 203-221.

[11] Clayton, R.L. and Werking, G.S. (1998): Business surveys of the future: The World Wide Web as a data collection methodology. In M. P. Couper et al. (Eds.): Computer Assisted Survey Information Collection. New York: John Wiley \& Sons, 543-562.

[12] Cohen, S. and Wills T.A. (1985): Stress, social support, and the buffering hypothesis. Psychological Bulletin, 2, 310-57. 
[13] Coomber, R. (1997): Using the Internet for survey research. Sociological Research Online, 2, http://www.socresonline.org.uk/2/2/2.html

[14] Couper, M.P. (2000): Web surveys: A review of issues and approaches. Public Opinion Quarterly, 4, 464-494.

[15] Couper, M.P. (2001): The promises and perils of Web surveys. In A. Westlake et al. (Eds.): The challenge of the Internet. London: Association for Survey Computing. Proceedings from the 'The Challenge of the Internet' conference, organized by Association for Survey Computing, Latimer Conference Centre, UK

[16] Couper, M.P., Traugott, M., and Lamias, M. (2001): Web survey design and administration. Public Opinion Quarterly, 65, 230-253.

[17] Dillman, D.A. (2000): Mail and Internet surveys. The Tailored Design Method. New York: John Wiley \& Sons.

[18] Ferligoj, A. and Hlebec, V. (1999): Evaluation of social network measurement instruments. Social Networks, 21, 111-130.

[19] Fisher, C.S. (1982): To dwell among friends: personal networks in town and city. Chicago: The University of Chicago Press.

[20] Franzen, A. (2002): Social capital and the new communication technologies. In J.E. Katz (Ed): Machines that become use. New Brunswick and London: Transaction Publishers, 105-116.

[21] Hammer, M. (1984): Explorations into the meaning of social network interview data. Social Networks, 6, 341-371.

[22] Hlebec, V. (1993): Recall versus Recognition: Comparison of Two Alternative Procedures for Collecting Social Network Data. In A. Ferligoj and T. Kramberger (Eds.): Developments in Statistics and Methodology, Metodološki zvezki, 9, Ljubljana: FDV, 121-128.

[23] Hlebec, V. and Ferligoj, A. (2002): Reliability of social network measurement instruments. Field methods, 14, 288-306.

[24] Hlebec, V., Lozar Manfreda, K., and Vehovar, V. (2002): Social Networks of Intensive Internet Users. Paper presented at Internet Research 3.0: NET / WORK / THEORY. Maastricht, The Netherlands.

[25] Hoffmeyer-Zlotnik, J.H.P. (1990): The Mannheim Comparative Network Research. In J. Weesie and H. Flap (Eds.): Social Networks Through Time. ISOR, Utrecht, 265-279.

[26] Holland, P.W. and Leinhardt, S. (1973): The structural implications of measurement error in sociometry. Journal of Mathematical Sociology, 3, 85111.

[27] Kogovšek, T., Ferligoj, A., Coenders, G., and Saris, W.E. (2002): Estimating the Reliability and Validity of Personal Support Measures: Full Information ML Estimation with Planned Incomplete Data. Social Networks, 24, 1-20. 
[28] Lozar Manfreda, K. (2001): Web Survey Errors. Doctoral dissertation. Ljubljana: Faculty of Social Sciences, University of Ljubljana.

[29] Lozar Manfreda, K. and Vehovar, V. (2002): Do Web and mail surveys provide same results? In A. Ferligoj and A. Mrvar (Eds): Development in Social Science Methodology. Metodološki zvezki, 18, Ljubljana: FDV.

[30] Lozar Manfreda, K., Batagelj, Z., and Vehovar, V. (2002): Design of Web Survey Questionnaires: Three Basic Experiments. Journal of Computer Mediated Communication,7. http://www.ascusc.org/jcmc/vol7/issue3/vehovar.html

[31] Lozar Manfreda, K., Koren, G., Vehovar, V., and Hlebec, V. (2004): Collecting data on ego-centered social networks on the Web: Methodological issues. Paper presented at Sunbelt Social Network Conference, Portorož, Slovenia.

[32] Marin, A. (2004): Are Respondents More Likely to List Alters with Certain Characteristics? Implications for Name Generator Data. Social Networks. Forthcoming.

[33] Marsden, P.V. (1987): Core Discussion Networks of Americans. American Sociological Review, 52, 122-31.

[34] Marsden, P.V. (1993): The reliability of network density and composition measures. Social Networks, 15, 399-421.

[35] Marsden, P.V. (2003): Interviewer effect in measuring networks size using a single name generator. Social Networks, 25, 1-16.

[36] Marsden, P.V. and Bailey, S. (1999): Interpretation and interview context: Examining the General Social Survey name generator using cognitive methods. Social Networks, 21, 287-309.

[37] Marsden, P.V. and Campbell, K.E. (1984): Measuring ties strength. Social Forces, 63, 482-501.

[38] Milardo, R.M. (1989): Theoretical and methodological issues in the identification of the social networks of spouses. Journal of Marriage and the Family, 51, 165-174.

[39] Neyer, F., Bien, W., Marbach, J., and Tempelton, R. (1991): Obtaining reliable network data about family life: A methodological examination concerning reliability of egocentered networks in survey research. Connections, 3, 14-26.

[40] Nie, N.H. and Erbring, L. (2002): Internet and Society: A Preliminary Report. IT \& Society, 1, 275-283.

[41] Straits, B.C. (2000): Ego's important discussants or significant people: an experiment in varying the wording of personal network name generator. Social Networks, 22, 123-140.

[42] Sudman, S. (1985): Experiments in the measurement of the size of social networks. Social Networks, 7, 127-151. 
[43] Sudman, S. (1988): Experiments in Measuring Neighbor and Relative Social Networks. Social Networks, 10, 93-108.

[44] Tracy, E.M. and Catalano, R.F. (1990): Reliability of social network data. Social Work Research and Abstracts, 26, 33-39.

[45] van der Poel, M. (1993): Personal Networks: A Rational Choice Explanation of their Size and Composition. Lisse: Swets \& Zeitlinger.

[46] van Groenou, M.B., van Sonderen, E., and Ormel, J. (1990): Test-retest reliability of personal network delineation. In C.P.M. Knipscheer and T.C. Antonucci (Eds.): Network Research: Substantive Issues and Methodological Questions. Amsterdam: Swets \& Zeitlinger, 121-136.

[47] van Tilburg, T. (1998): Interviewer effects in the measurement of personal network size. Sociological Methods \& Research, 26, 300 -29.

[48] Vehovar, V., Batagelj, Z., Lozar Manfreda, K., and Zaletel, M. (2002): Nonresponse in Web Surveys. In R.M. Groves, D.A. Dillman, J.L. Eltinge, and R.J.A. Little (Eds.): Survey Nonresponse. New York: John Wiley \& Sons, 229-242.

[49] Wellman, B. and Wortley, S. (1990): Different Strokes from Different Folks: Community Ties and Social Support. American Journal of Sociology, 96, 55888.

[50] Zemljič, B. and Hlebec, V. (2001): Zanesljivost mer središčnosti in pomembnosti v socialnih omrežjih. Družboslovne razprave, 17, 191-212. 